\title{
3D character of backward erosion piping: Small-scale experiments
}

\author{
K. Vandenboer \\ Ghent University, Ghent, Belgium
}

\author{
A. Bezuijen \\ Ghent University, Ghent, Belgium/Deltares, Delft, The Netherlands \\ V.M. van Beek \\ Deltares/Delft University of Technology, Delft, The Netherlands
}

\begin{abstract}
Backward erosion piping is an important failure mechanism for cohesive water retaining structures which are founded on a sandy aquifer. At present, the prediction models for safety assessment are often based on 2D assumptions. In this work, the 3D character of the phenomenon is demonstrated on the basis of small-scale experiments. Our approach reveals the correlation between the occurrence of piping initiation and progression and the width of the physical model, which is a measure for the inclusion of the third dimension (to be regarded in a real dike situation as the influence zone of a crater). In addition, it was found that the model width has an impact on pipe characteristics and pipe development. Therefore, our results enable a better understanding of the complex physical mechanism related to backward erosion piping and thus can lead to a significant improvement in the safety assessment of water retaining structures.
\end{abstract}

\section{INTRODUCTION}

\subsection{Backward erosion piping}

Backward erosion piping is an important failure mechanism for cohesive water-retaining structures which are founded on a sandy aquifer. A local disruption of the downstream top layer leads to concentrated seepage flow towards the opening. This entails high local hydraulic gradients causing upward forces on the sand grains which may result in the onset of erosion at that particular location (pipe initiation). The erosion process continues in the upstream direction, resulting in the formation of shallow pipes in the sand layer (pipe progression). These pipes do not collapse because of the bridging nature of the overlying cohesive material.

The term 'backward erosion piping' is designated to the growth direction of the pipes which is opposite to the flow direction, i.e. from downstream to upstream. Eventually, the pipe forms a direct connection between upstream and downstream, which leads to a facilitated water transport and to the action of accelerated erosion. The pipe finally reaches unbridgeable dimensions resulting in a (partial) collapse. See Figure 1.

\subsection{Current formulae}

Different models exist for the safety assessment of a water-retaining structure regarding piping failure.

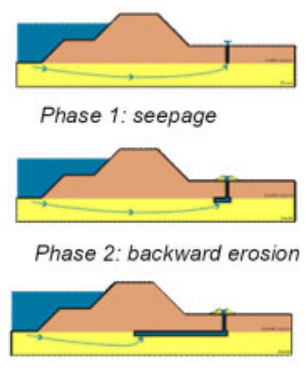

Phase 2: backward erosion

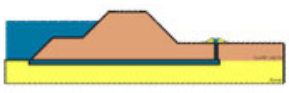

Phase 3: widening of pipe

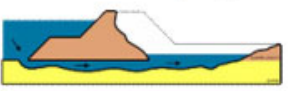

Phase 4: failure of the levee

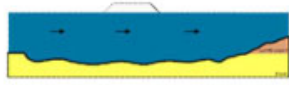

Phase 4: breakthrough
Figure 1. Backward erosion piping, copied with permission from (van Beek, et al. 2011).

Nowadays, Sellmeijer's prediction model is often used to estimate the critical gradient at which backward erosion piping leads to failure, see equation 1 (Sellmeijer and Koenders 1991; Sellmeijer 1988).

$$
\frac{H_{c r}}{L}=F_{R} \cdot F_{S} \cdot F_{G} \cdot F_{F}
$$

With $\mathrm{F}_{R}, \mathrm{~F}_{S}$ and $\mathrm{F}_{G}$ the resistance factor, the scale factor and the geometrical shape factor respectively:

$$
F_{R}=\eta \frac{\gamma_{p}^{\prime}}{\gamma_{w}} \tan \theta
$$




$$
F_{S}=\frac{d_{70}}{\sqrt[3]{\kappa L}}
$$

$$
\begin{aligned}
& F_{G}=\left(\frac{D}{L}\right)^{\frac{0.28}{\left(\frac{D}{L}\right)^{2.8}-1}} \\
& F_{F}=0.68-0.1 \cdot \ln \left(F_{S}\right)
\end{aligned}
$$

and $\gamma_{p}^{\prime}$ the submerged unit weight of particles, $\gamma_{w}$ the unit weight of water, $\eta$ the coefficient of White, $\theta$ the bedding angle, $d_{70}$ the particle diameter, $D$ the height of the sand layer, L the width of the water-retaining structure and $\kappa$ the intrinsic permeability.

The formula was obtained by a combination of analytical formulae, 2D FEM simulations for modelling groundwater flow, observations on critical pipe lengths from piping experiments and curve fitting. The criterion for onset of erosion is the equilibrium of sand grains at the pipe bottom under the action of water flow within the pipe according to White (White 1940) in 2D.

In situations which are similar to those forming part of the study that led to the formula, the prediction model is successful (which was ensured by curve fitting of the formula to the results of 3D experiments). But recent experiments indicate that this original Sellmeijer formula fails to predict the critical head correctly under different constraints and an empirical correction has been proposed (Sellmeijer, et al. 2011). However, a theoretical explanation remained forthcoming so far.

In this work, the effect of the 2D assumption, relied upon in both the groundwater flow calculations and the erosion incentive, is studied.

\subsection{D assumption}

Basically, a 2D assumption invokes that the water which actively contributes to the erosion mechanism, originates from a vertical $2 \mathrm{D}$ plane. Hence the water supply that is considered in the calculations is limited to this vertical plane and water resources of adjacent areas are ignored. Furthermore, water influx from the sandy aquifer into the pipe is only possible through the pipe tip and bottom, not from the sides.

In order to perform a 2D experiment, an infinitesimal width must be chosen. Generally, a finite width is used to investigate the phenomenon backward erosion piping (De Wit, et al. 1981; Hanses, et al. 1985; Miesel 1978; Sellmeijer 1981; van Beek, et al. 2011). In this paper, the influence of the model width, which is a measure of the presence of the third dimension, is investigated by performing a series of experiments with different widths and relating them to the obtained critical hydraulic heads.
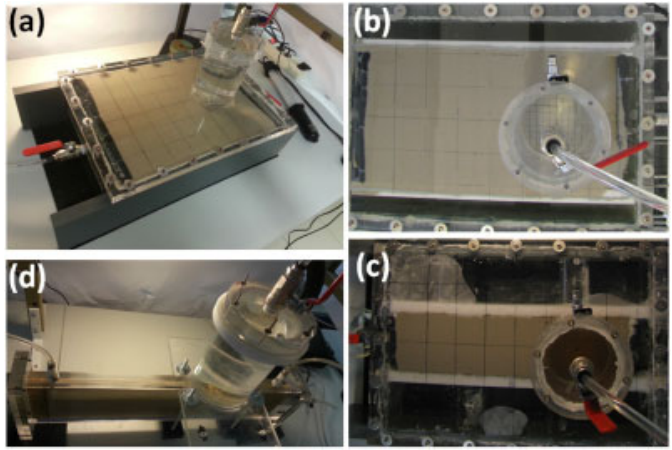

Figure 2. Experimental setup: $\mathrm{W}=30 \mathrm{~cm}$ (a), $\mathrm{W}=20 \mathrm{~cm}$ (b), $\mathrm{W}=10 \mathrm{~cm}$ (c) and $\mathrm{W}=1 \mathrm{~cm}(\mathrm{~d})$.

\section{M32}

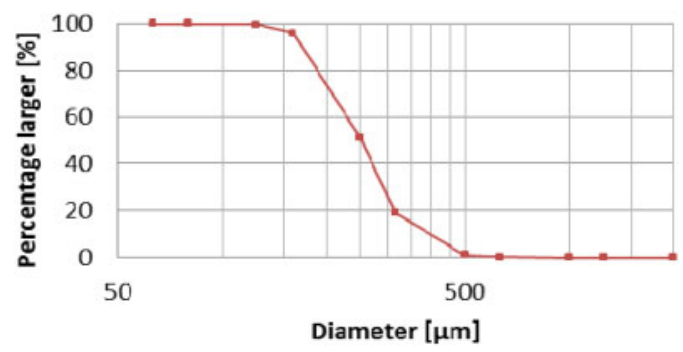

Figure 3. Grain size distribution M32 sand.

\section{EXPERIMENTAL STUDY}

\subsection{Experimental setup \& method}

In laboratory conditions, the sandy aquifer is built in a pvc box, the cohesive water-retaining structure is replaced by a Perspex plate (see Figure 2) with a fixed circular opening representing a locally punctured top layer and the hydraulic gradient is applied by means of an upstream and downstream reservoir with adjustable water levels.

The sand sample is prepared by pouring dry sand into the box filled with water in vertical position and tamping continuously. In this way a homogeneous sand package with relative density RD of more or less $90 \%$ is obtained. The sand used in this study is silica sand of Mol, sieved into a quite uniform distribution with a mean grain size diameter of $250 \mu \mathrm{m}$ (Figure 3 ) and is denoted fraction M32. The sand sample in the box has a length of $40 \mathrm{~cm}$ (between the upstream and downstream water-permeable filters), a height of $10 \mathrm{~cm}$ and a width varying between $1 \mathrm{~cm}$ and $30 \mathrm{~cm}$. The distance from the upstream filter to the circular opening amounts $30 \mathrm{~cm}$.

The replacement of the cohesive water-retaining structure by a transparent Perspex plate enables to observe the development of the erosion pipe. In this study a circular exit was used in order to obtain a reproducible pipe formation: in case of a plane type exit or a ditch type exit (Beek, et al. 2013), each pipe also 
originates at one point downstream, but neither the location, nor the number of pipes is controllable. The hole type exit has a diameter of $5 \mathrm{~mm}$, which is 20 times the mean grain size, and a height of $10 \mathrm{~mm}$, for practical reasons. A Perspex cylinder is placed around the hole type exit and connects it to the downstream reservoir.

The upstream reservoir is maintained at a constant water level by means of a pump and an overflow, while the downstream reservoir is a tube with a bended exit with an adjustable level.

At the beginning of the experiment, the in- and outlet water levels are equal which corresponds to a hydraulic head $\Delta \mathrm{H}$ of $0 \mathrm{~cm}$. The hydraulic head is increased in steps of $0.5 \mathrm{~cm}$ or $1 \mathrm{~cm}$ every 5 minutes by lowering the downstream reservoir, as long as no erosion takes place. When the critical hydraulic head for initiation is exceeded, sand grains start to move and the hydraulic head is kept constant. A pipe forms in the direction of the upstream filter, up to a certain length where it reaches an equilibrium state. If no erosion is observed for at least 5 minutes, the hydraulic head is increased again, usually resulting in progression of pipe growth. This process is repeated several times, until the 'critical hydraulic head for progression' is exceeded, i.e. no equilibrium state is achieved and the pipe grows until it reaches the upstream filter, called breakthrough. Finally the widening phase starts in which the pipe deepens and widens due to the facilitated water flow through the fully-formed pipe. For this study, we are interested in the initiation and progression phase so the test is stopped at the moment of breakthrough.

The eroded sand is deposited around the circular exit and forms a crater at that location. The development of the pipe is captured by means of a camera installed above the setup, taking photos at a fixed time interval. The seepage water is collected on a balance in order to measure the flow rate continuously.

\subsection{Results}

Experiments have been performed with a model width of $30 \mathrm{~cm}, 20 \mathrm{~cm}, 10 \mathrm{~cm}$ and $1 \mathrm{~cm}$, in order to investigate the influence of this width and consequently the three dimensional character of the backward erosion process.

For all model widths, the pipe developed in stages. Some photos of these different stages of development are shown in Figure 4 until Figure 7 for the different model widths. The approximate pipe contours are added in green.

These photos reveal a first result of this study: the meandering character of the pipe increases with the model width. The meandering of the pipe can be attributed to the search for weak links in the granular structure of the sand (Weijers 1993). For larger widths, water supply towards the pipe originates from a wide filter upstream and bends towards the pipe (as illustrated in Figure 8). Therefore, all grains around the pipe tip are prone to piping and the path with least

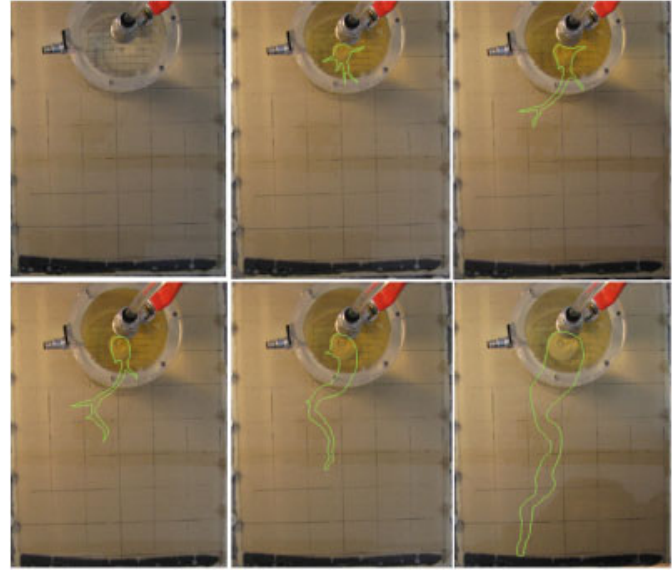

Figure 4. Different stages of pipe development for a model width $\mathrm{W}=30 \mathrm{~cm}$.
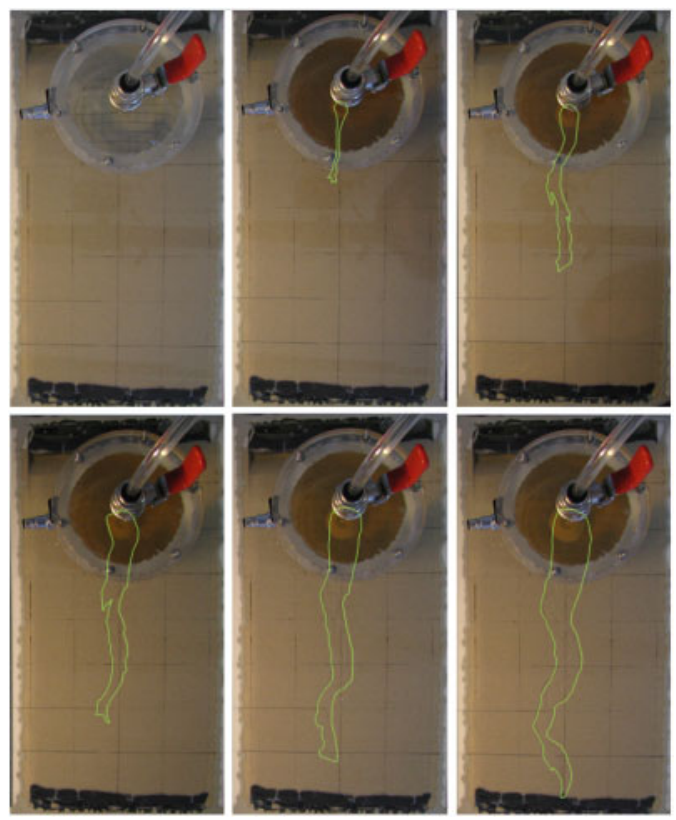

Figure 5. Different stages of pipe development for a model width $\mathrm{W}=20 \mathrm{~cm}$.
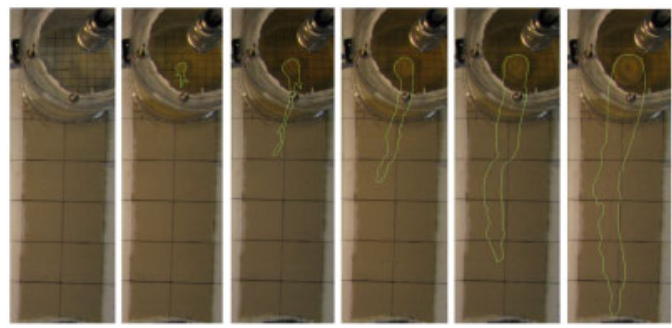

Figure 6. Different stages of pipe development for a model width $\mathrm{W}=10 \mathrm{~cm}$. 


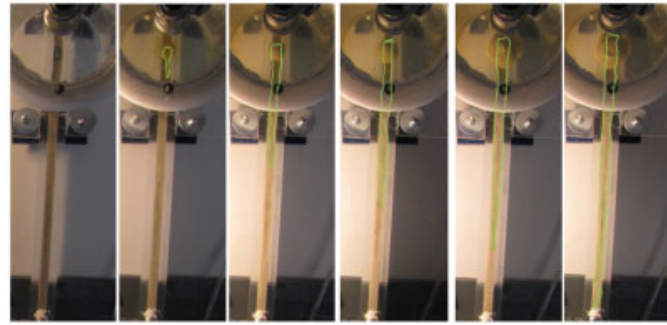

Figure 7. Different stages of pipe development for a model width $\mathrm{W}=1 \mathrm{~cm}$.
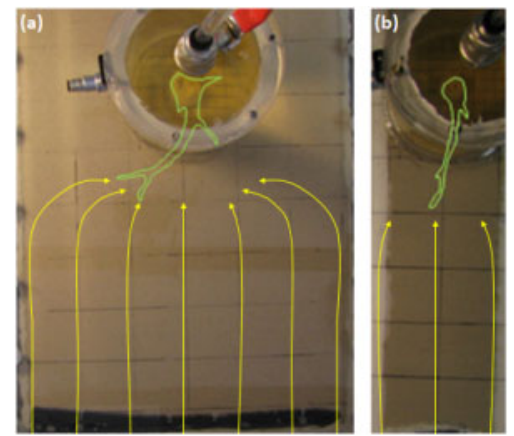

Figure 8. Possible flow paths for $\mathrm{W}=30 \mathrm{~cm}$ (a) and $\mathrm{W}=10 \mathrm{~cm}(\mathrm{~b})$.

resistance can be followed. In case of a small model width on the other hand, flow paths are not bended as much, so the chance for meandering decreases and the course of the pipe to the upstream filter is more or less straight (see Figure 8). In case of a width of $1 \mathrm{~cm}$, meandering is simply not possible because of the limited width.

Although the area in which the pipe migrates increases for an increasing model width due to meandering, the pipe width itself does not seem to change with the model width (again except for the model width of $1 \mathrm{~cm}$, where the pipe width is limited due to the boundaries). As a consequence, the pipe width seems to be independent of the model width.

The critical hydraulic head for piping initiation and for piping progression are plotted as a function of the model width in Figure 9. It is clear that both the critical head for initiation and the critical head for progression decrease with an increasing model width. This means that piping is more likely to occur in a sandy aquifer with a larger width. This is also attributable to the wider area of water supply: at a specific hydraulic head, the volume of water flowing through the setup and thus through the outflow opening with a diameter of $5 \mathrm{~mm}$, is higher for larger model widths. This increased amount of water flow exerts higher forces on the sand grains in the pipe and outflow opening and therefore facilitates erosion. The observed trend is not linear and seems to stagnate for an increasing model width. This can be understood as follows: when increasing the model width infinitely, the bended flow

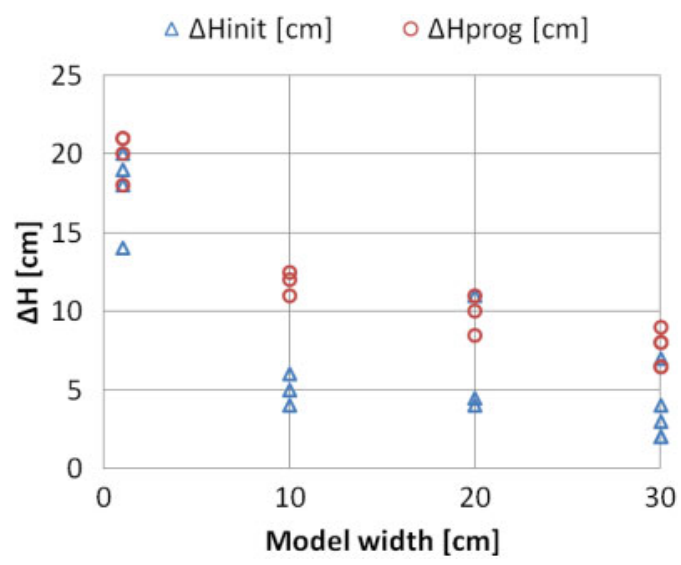

Figure 9. Critical hydraulic head for piping initiation and progression as a function of the model width.

paths become infinitely long, so their contribution to the amount of flow becomes negligible. In that case it is more advantageous to supply this water to another, nearer outflow opening. This is observed in case of a ditch or plane type exit: multiple pipes grow simultaneously at a certain distance from each other (Knoeff, et al. 2010; Miesel 1978; van Beek, et al. 2010; Weijers 1993).

It is noted that, in our test series, the critical head for initiation is usually lower than the critical head for progression (as opposed to equal). This means that after piping initiation, the pipe reaches equilibrium at least once, before breaking through at the critical hydraulic head.

Figure 10 shows the flow rate $\mathrm{Q}$ as a function of the applied hydraulic head. The Darcy law states that the flow rate increases linearly with the hydraulic head, but during piping erosion, the overall permeability increases, resulting in a higher flow rate. This can be clearly observed at the end of each experiment: when the pipe reaches the upstream reservoir, the resistance is so small that the curves in Figure 7 rise vertically. At this moment the widening phase starts. At earlier stages of pipe development, this is more difficult to observe, but Figure 7 shows that the ratio between the flow rate and the applied hydraulic head, which is a measure for the change of permeability of the sand package, increases during the experiment.

Although some scatter is observed in the graphs due to the stochastic character of the phenomenon on micro scale, the different model widths clearly differentiate themselves in groups, revealing the different behavior of backward erosion piping for different model widths.

In the pipe length is plotted as a function of the applied hydraulic head. It is noted that this pipe length is the 'straight' pipe length and not the curved pipe length which can be longer.

For larger model widths, the piping development was more gently: when increasing the hydraulic head, the pipe grew over a small distance and then reached 


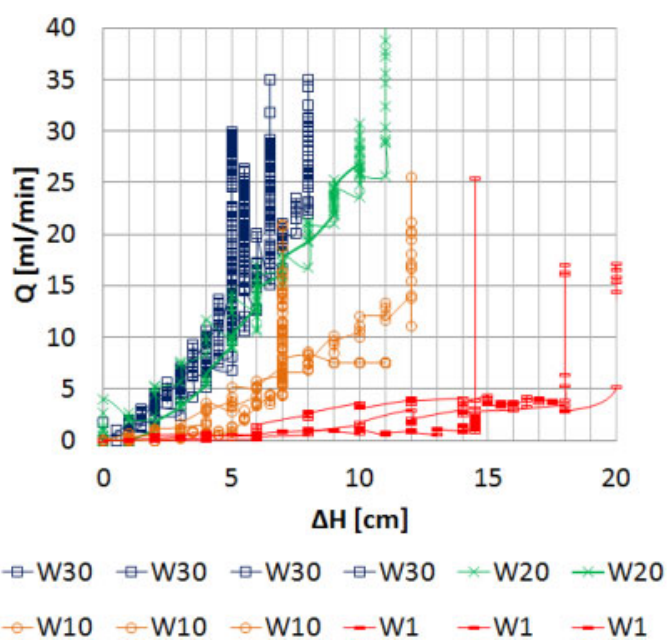

Figure 10. Flow rate $\mathrm{Q}[\mathrm{ml} / \mathrm{min}]$ as a function of hydraulic head $\Delta \mathrm{H}[\mathrm{cm}]$.

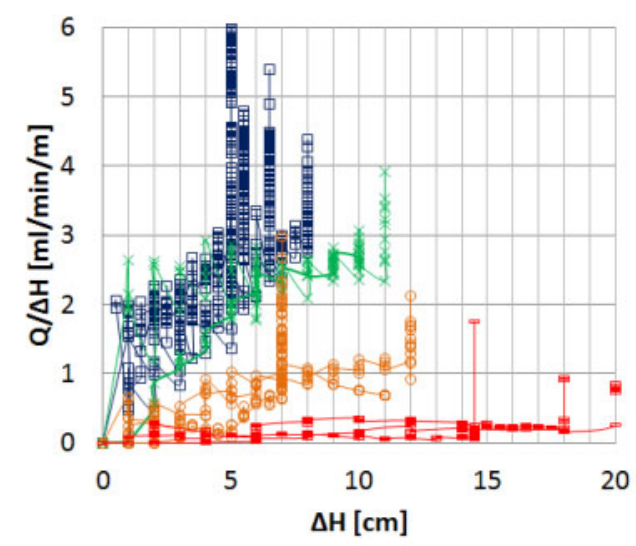

$$
\begin{aligned}
& -\mathrm{W} 30-\mathrm{W} 30-\mathrm{W} 30-\mathrm{W} 30-\mathrm{W} 20 \div \mathrm{W} 20 \\
& -\mathrm{W} 10-\mathrm{W} 10-\mathrm{W} 10-\mathrm{W} 1-\mathrm{W} 1-\mathrm{W} 1
\end{aligned}
$$

Figure 11. Measure of permeability $\mathrm{Q} / \Delta \mathrm{H}[\mathrm{ml} / \mathrm{min} / \mathrm{cm}]$ as a function of hydraulic head $\Delta \mathrm{H}[\mathrm{cm}]$.

equilibrium; this happened a few times until the critical hydraulic head was reached and the pipe suddenly progressed to the upstream side. For smaller model widths, equilibrium stages did not occur often. This is also clear from Figure 12. Also, the difference between the hydraulic head for progression and the hydraulic head for initiation, on average, increases for increasing widths (can be deduced from Figure 9).

The so-called critical pipe length, i.e. the pipe length which, once surpassed, is not followed by equilibrium anymore if the hydraulic head is kept constant, varies for the different experiments between $0 \mathrm{~cm}$ and $9 \mathrm{~cm}$. This does not fully correspond with the generally adopted value between L/3 and L/2 (MüllerKirchenbauer, et al. 1993), which is between $10 \mathrm{~cm}$ and $20 \mathrm{~cm}$ respectively for our setup. However, it is

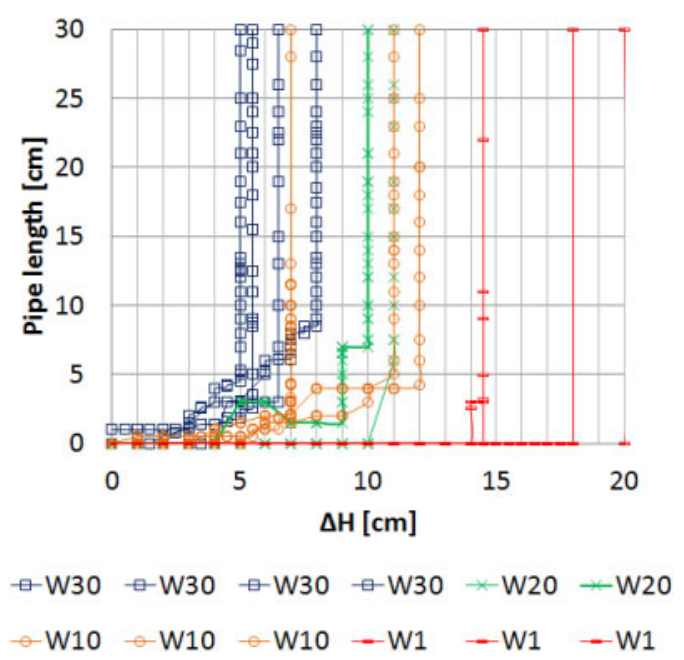

Figure 12. Pipe length $\mathrm{L}[\mathrm{cm}]$ as a function of hydraulic head $\Delta H[\mathrm{~cm}]$.

possible that a larger critical length would be obtained if $\Delta \mathrm{H}$ would be increased in smaller steps.

\section{DISCUSSION}

It was found that both the critical head for initiation and the critical head for progression decrease with an increasing model width. This means that piping is more likely to occur in a sandy aquifer with a larger width. This can be understood by noting that it is the concentration of flow lines towards the outflow opening or towards the pipe which causes high local gradients exerting forces on the sand grains and resulting in erosion. When increasing the width of the model, the area from which the water supply originates increases, resulting in a higher amount of water contributing to the erosion phenomenon and consequently a denser concentration of flow lines close to the outflow opening or to the pipe surroundings in case of piping initiation and piping progression respectively.

The results show that neglecting the third dimension of backward erosion piping results in imprecise predictions on the safety of water-retaining structures with respect to backward erosion piping. Furthermore, research on backward erosion piping based on a 2D approach of any kind, inevitably leads to poor understanding of the phenomenon. When establishing an improved design formula, these results must be taken into account since a design formula based on a $2 \mathrm{D}$ assumption, misses important aspects of backward erosion piping attributable to its $3 \mathrm{D}$ nature.

Apart from this analysis, some observations already revealed the 3D character of the phenomenon. Firstly, the eroded pipes have a finite width, which is larger than the diameter of the outflow opening and generally decreases with the distance from downstream (van Beek, et al. 2014). It is impossible to account for the width of the pipe in a $2 \mathrm{D}$ reasoning. 
Secondly, the degree of meandering varies for different widths, meaning that the third dimension has a certain influence on the pipe trail and dimensions. Furthermore, the phenomenon meandering is already a 3D feature, which cannot be captured in a 2D approach. On the other hand, the pipe width itself does not significantly depend on the model width, as long as enough space is provided.

Finally, the progress of the pipe development differs for different model widths. For larger model widths, the pipe develops more gradually: when increasing the hydraulic head, the pipe grows over a small distance and reaches equilibrium; this happens a few times until the critical hydraulic head is reached. This is not the case for smaller model widths, where the pipe often reaches the upstream filter in a few steps. As a result, the difference between the critical hydraulic head for initiation and progression is smaller in the latter case, so initiation becomes more normative as the model width decreases. This means that the presence of the third dimension is of high importance for initiation of piping, which can be understood as follows: at the initiation stage, the water needs to travel over a longer distance through the soil, so every contribution of water coming from the sides helps. When the pipe grows, the distance the water needs to travel decreases and thus, the contribution of water flow from the sides becomes less critical for pipe progression.

\section{CONCLUSIONS AND FUTURE WORK}

An experimental study on backward erosion piping revealed that the model width has an important influence on the critical hydraulic gradient: a larger model width requires a smaller hydraulic gradient for both initiation and progression. The results can be understood based on a simple reasoning: a greater width results in more water supply and consequently higher local hydraulic gradients leading to erosion. Furthermore, the model width has an impact on the degree of pipe meandering and on the progress of pipe development. The width of the model can be considered to be a measure for the third dimension, besides the length dimension and the height dimension of the setup. From this study it can be concluded that backward erosion piping is a three dimensional phenomenon. It is important to take this into account when studying this phenomenon, because two dimensional approaches miss some important aspects of the phenomenon and might lead to erroneous understanding.

Future work includes the study of backward erosion piping on micro scale in addition to macro scale in order to further understand the erosion processes on grain size level leading to macro processes as pipe growth, meandering, etc.

\section{ACKNOWLEDGEMENTS}

The authors like to thank ir. Lies Dolphen, who performed a part of the test series.

\section{REFERENCES}

Beek, V.M. van, A. bezuijen, and H. Sellmeijer 2013. Backward Erosion Piping. In Erosion in Geomechanics Applied to Dams and Levees. S. Bonelli, ed. Pp. 193-269. London: Wiley.

De Wit, J.M., J.B. Sellmeijer, and A. Penning 1981. Laboratory testing on piping.

Hanses, U., H. Müller-Kirchenbauer, and S. Savidis 1985. Zur Mechanik der rückschreitenden Erosion unter Deichen und Dämmen. In Bautechnik. Pp. 6. Berlin: Wilhelm Ernst \& Sohn.

Knoeff, J.G., V.M. van Beek, and U. Förster 2010. Observations of piping on the Ijkdijk testdike in the Netherlands.

Miesel, D. 1978. Rückschreitende Erosion unter bindiger Deckschicht, Berlin, 1978.

Müller-Kirchenbauer, H., M. Rankl, and C. Schlötzer 1993. Mechanism for regressive erosion beneath dams and barrages. In Filters in geotechnical and hydraulical engineering. H.S. Brauns, ed. Pp. 369-376. Rotterdam: Balkema.

Sellmeijer, H., et al. 2011. Fine-tuning of the backward erosion piping model through small-scale, medium-scale and IJkdijk experiments. European Journal of Environmental and Civil Engineering 15(8):1139-1154.

Sellmeijer, J. B., and M. A. Koenders 1991. A mathematical model for piping. Applied Mathematical Modelling 15(11-12):646-651.

Sellmeijer, J.B. 1981. Piping due to flow towards ditches and holes. Euromech 143, Delft, 1981.

Sellmeijer, J.B. 1988. On the mechanism of piping under impervious structures, PHD-thesis, TU Delft.

van Beek, V. M., et al. 2010. Levee failure due to piping: a full-scale experiment.

van Beek, V. M., H. Knoeff, and H. Sellmeijer 2011. Observations on the process of backward erosion piping in small-, medium- and full-scale experiments. European Journal of Environmental and Civil Engineering 15(8):1115-1137.

van Beek, V.M., et al. 2014. Investigation of the backward erosion mechanism in small-scale experiments. 8th international conference on Physical Modelling in Geotechnics 2014, Perth, Australia, 2014.

Weijers, J.B.A., Sellmeijer, J.B. 1993. A new model to deal with the piping mechanism. In Filters in geotechnical and Hydraulical Engineering. H.S. Brauns, ed. Pp. 349-354. Rotterdam.

White, C. M. 1940. The equilibrium of grains on the bed of a stream. Proceedings Royal Society, London, 1940. Vol. 174A, Pp. 322-338 